\title{
The Implications of Fluorescent Lamp Electronic Ballast Dimming -An Experimental Study
}

\author{
Sheryl G. Colaco ${ }^{1}$, Ciji P. Kurian², V. I. George ${ }^{1}$, Anitha M. Colaco ${ }^{3}$ \\ ${ }^{1}$ Department of Instrumentation \& Control Engineering, Manipal Institute of Technology, Manipal, India \\ ${ }^{2}$ Electrical \& Electronics Engineering, Manipal Institute of Technology, Manipal, India \\ ${ }^{3}$ Electrical \& Electronics Engineering, NMAMIT, Nitte, India \\ Email: sheryl_grace2001@yahoo.co.in
}

\begin{abstract}
In recent years, fluorescent lamp dimming controls are an integral part of daylight artificial light integrated schemes intended for realization of energy savings. However, dimming, like any lighting option, presents its own particular challenges and potential tradeoffs. In view of this, the present manuscript depicts the preliminary work progress carried out to arrive at a comprehensive idea on dimming implications on key factors: electrical characteristics, photometric distributions of lighting systems and influence on quality as well as quantity of visual environment. The objective is to experimentally establish the acceptable range of dimming control voltage that would satisfy both electrical and photometric performance of luminaire. The vital part of the paper is devoted towards presentation of measurement results. For the experimental analysis, three representative samples of different commercial analog 1-10VDC electronic dimmable ballasts and fluorescent fixtures are compared and evaluated over their control voltage dimming range.
\end{abstract}

Keywords: dimming, power factor, power quality, chromaticity, light intensity, illuminance

\section{Introduction}

In the present scenario, electronic dimming ballasts are crucial in automatic control and dimming function for energy-management applications such as daylight harvesting [1]. Over many years, in spite of many reports and case studies cite the advantages of daylight linked automatic light dimming systems; comparatively very less schemes have been implemented [2,3]. Part of the reason could be attributed to the issues associated with lamp dimming that have been debated during the last few years. A number of literatures in print state that at some stage during deep dimming; electronic dimming ballast exhibit poor performance reflected by dramatic deterioration of electric and photometric characteristics [4] Important concerns related to dimming include lamp life, perceived brightness, perception of light level reduction, color shift, power quality and energy efficiency [3]. Many past studies address these issues separately. The effect of dimming on lamp life was investigated by Tetri and Gligor [5]. Their experimental results indicate that mortality was higher in the dimmed test groups than in the undimmed test groups. Further their lamp life test result showed that with electronic ballasts lamps reached their nominal life even if the lamps are dimmed statically or dynamically. A study by Akashi et al. [6] on the detection and acceptability of temporarily reduced light levels showed that a reduction of $15 \%$ in illuminance levels is the approximate threshold for noticing changes under typical office lighting conditions. Further their study revealed, light level reductions that are deemed acceptable in an office environment ranges from approximately $33 \%$ to $50 \%$ depending on the office task and whether the occupants were aware of the purpose and benefits of dimming. Literature reports and utilities show an increased concern about the power quality aspects due to dimming of electronic ballasts [7,8]. Experimental tests performed by National Lighting Product Information Program (NLPIP)[9] on electronic dimmable ballasts of $\mathrm{T} 8$ and CFL lamps document that progressive decrease in dimming levels are associated with increase in voltage as well as current THD accompanied by corresponding diminishing of power factor at minimum light output. In their separate experimental study conducted by Benoit et al. [10] and Doulos et al. [11] showed that power factor decreases in function of dimming depth due to subsequent setting up of harmonics while dimming. Further, inorder to quantify energy savings from dimming ballasts Doulos et al. [11] performed various sets of electrical and illuminance measurements on eighteen commercial 
ballasts at different dimming levels. The authors [11] developed polynomial functions between light output and consumed power to reckon the relative differences in energy savings. The chromaticity of a fluorescent lamp is a supplementary parameter used to gauge light quality. The adverse effect of dimming when it lowers the luminous efficacy of the light source or changes its colour requires careful inspection. The present communication reports the preliminary study of an ongoing research project on promotion of daylighting for energy conservation in a daylight artificial light integrated scheme. This paper is organized as follows. Following a brief discussion on problem statement in Section 2, the main sections of this paper includes experimental methodology in Section 3, presentation of measurement results in Section 4 and finally, brief conclusions are deduced in Section 5. It is envisaged that the information from these studies would be of assistance to architect, the engineer, the lighting designer or a combination of these during the initial stage when different daylighting schemes and concepts are being developed.

\section{Problem Statement}

The performance characteristic of lamps and ballasts usually vary from one manufacturer to another. Therefore prior to new lighting installations not only choice of the lamp make is important but also there is a need to study electrical and photometric characteristics of luminaire. Obviously this could also serve as an important starting datum for analysis and optimization of installations performances in buildings. Issues related to electronic ballast dimming on fluorescent lamp and visual performance characteristics are the subject considered for discussions in this paper. This paper seeks to put into perspective the subject of fluorescent lamp dimming in a manner that has not been discussed previously. The intention is to ascertain the preferable range of ballast control signal voltage that does not deteriorate electrical characteristics, photometric distributions of lighting systems and visual environment quality as well as quantity. For practical evaluation, three separate analogs dimming ballast each supplied by different manufacturer and most commonly employed for daylight responsive dimming applications in Indian offices are analyzed.

\section{Experimental Methodology}

The methodology developed in this work combines electrical; and photometric measurements including computer simulations. The customary testing and measurement procedures specified by CIE and IESNA were followed [12-15]. The experimental tests were performed under a standard set of conditions at the Photometry Laboratory of Manipal Institute of Technology, Manipal (India). Three $230 \mathrm{~V}, 2 \times 36 \mathrm{~W}$ analog electronic dimming ballasts with corresponding pairs of T8 fluorescent lamps supplied by 3 different manufacturers Osram, Wipro \& Philips (labeled in this paper as EDB-A, EDB-B, EDB-C respectively) were examined for practical comparison and evaluation. In order to assess the performance characteristic during dimming; twin 36W fluorescent lamps were dimmed by manual adjustment of dimming ballast control signal DC voltage from 1 to $10 \mathrm{~V}$ (up or down) with a digital $0-30 \mathrm{~V}$ regulated DC power supply. Prior to taking measurements the tested lamps were pre burned for full light output for 100 hours before dimming with a supply voltage of $230 \mathrm{~V}$ a.c. $50 \mathrm{~Hz}$ and ballast control voltage of $10 \mathrm{~V}$. The adjustment from one dimming level to another level was done gradually. The lamps were tested on 10 different ballast control voltages in step difference of 1 volt. To ensure that the temperature of each lamp stabilized during testing, at each control voltage level the lamps were operated for at least $10 \mathrm{~min}$. All the measurements were performed at an ambient temperature of $26^{\circ} \mathrm{C} \pm 2^{\circ}$ with a stabilized line voltage of $230 \mathrm{~V}$ a.c.

To assess the performance characteristics; dimming ballast control voltage (1-10V DC) formed the variable parameter. The dependent variables include electrical parameters (i.e., current, power factor, active power, voltage and current harmonics) and photometric parameters (i.e., luminous intensity, CCT, CU, chromaticity). The following measurements were carried out to provide the technical background for evaluating the electric and photometric characteristics of tubular fluorescent lamp systems all through dimming control signal voltage range of electronic dimming ballast.

The luminous flux of the lamp in each dimming mode was measured in an integrating sphere with an inner diameter of $2.0 \mathrm{~m}$. Power line voltage and line current harmonic spectrum together with active power, apparent power and power factor was recorded using FLUKE 43B power quality analyzer. Lamp Chromaticity coordinates were gauged using Konica Minolta CL-200 Chroma meter contained in a Color chromaticity coordinate measuring unit. The estimation of luminaire luminous light intensity in C0-180 and C 90-270 planes involved collection of illuminance data in both the specified planes in a darkroom at a fixed distance of $5 \mathrm{~m}$ from luminaires mounted on a swing arm Goniophotometer. The luminous intensity was then calculated from preceding illuminance measurement using the inverse square distance law. Lighting calculation software that this authors typically uses are AGI 32 photometric toolbox for computation of CU chart and Relux light simulation software for rendering of results for visualization of the effects of dimming on quality and quantity of illuminance in an interior. Luminaire candela power distribution plots and 3D mesh plots of work plane illuminance distribution were obtained using Matlab; a computational software [16]. 


\section{Presentation of Measurement Results}

Analog electronic dimming ballasts permit the light output of the lamp to be continuously controlled over a range of approximately $1 \%$ to $100 \%$ of full light output.The main method of analog control utilizes a low voltage control signal in the range $1-10 \mathrm{~V}$ dc. A separate pair of control cables runs from the controller to luminaires in the controlled group. Dimming is accomplished by adjustment of control signal voltage of the ballast. This modifies the amplitude of current flow in the fluorescent lamp to achieve variation in emitted lamp light output. Consistent dimming behaviour varies among different ballasts made by different manufacturers. The ensuing subsections enumerate the impacts of dimming on performance characteristics of fluorescent lamps.

\subsection{Effect on Electrical Characteristics}

Figures 1(a) and 1(b) illustrate the decrease in current and subsequently reduction in power consumption during dimming down from $10 \mathrm{~V}$ to $0 \mathrm{~V}$. All the reported ballast lighting system has a maximum active power consumption of approximately $72 \mathrm{~W}$. During dimming down process the reduction in active power consumption ranges from a maximum of $100 \%$ at $10 \mathrm{~V}$ to a minimum of $16 \%, 19 \%$ and $17 \%$ at $0 \mathrm{~V}$; for ballasts EDB-A, EDB-B and EDB-C respectively. Figures 1(c) and 1(d) depict the variation of percentage light output as a function of control voltage and percentage input power re- spectively. It is noted that for all the ballasts neither the light output nor the system power consumption has a linear relationship with control voltage. Studies of Choi et al. [17] report that this nonlinear variation in light output with different dimming control voltage is one among many other reasons for unreliability and inaccuracy of daylight dimming systems, seeing that a particular control voltage cannot be predicted when a certain light output is required. In order to achieve performance consistency of electronic dimming ballast especially for PC based light control algorithms, authors [17] suggests the application of best fit functions using regression methods that would satisfy the relationship between control voltage of dimming ballast and its corresponding light output characteristics. As seen form Figure 1(d), at a control voltage of $0 \mathrm{~V}$; all the test lamps emit approximately $1 \%$ of light output with a minimum power consumption of approximately $20 \%$. It is noticed during the experiment that neither the lamp extinguishes nor flickers at minimum control voltage. Figure 1(e) shows the variation of luminous efficacy as a function of percentage active power consumption. The luminous efficacy drops from a maximum of $43 \%, 45 \%$ and $42 \%$ to a minimum of approximately 1\% for EDB-A, EDB-B and EDB-C lamps respectively. It is also observed from Figure 1(e) that luminous efficacy of all the tested lamps stays approximately constant with dimming until about $57 \%$ of input power; thereafter it decreases drastically.

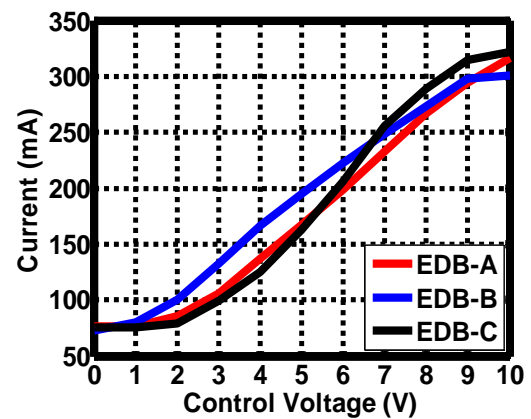

(a)

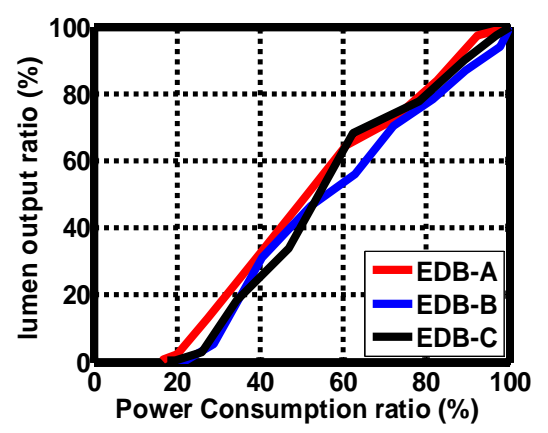

(d)

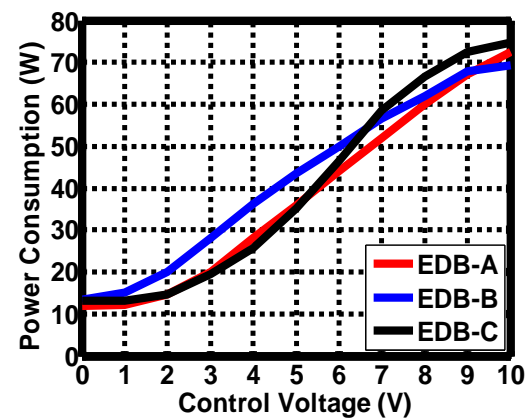

(b)

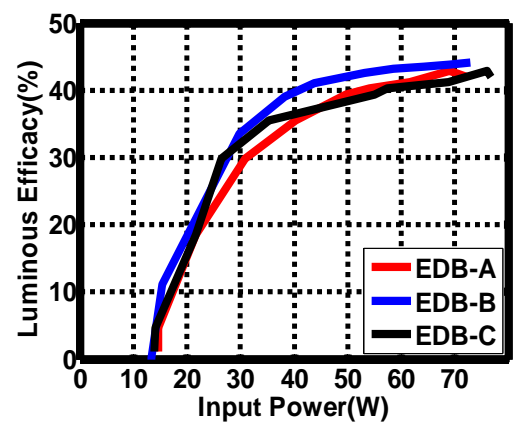

(e)

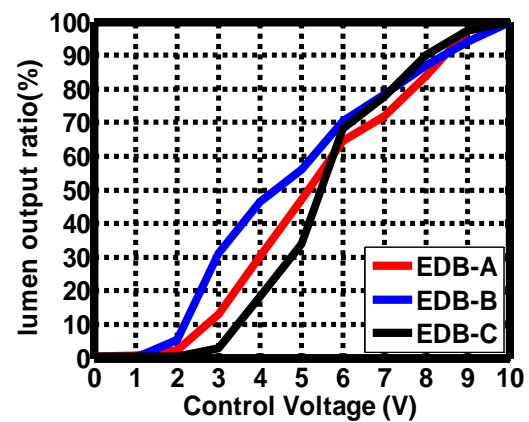

(c)

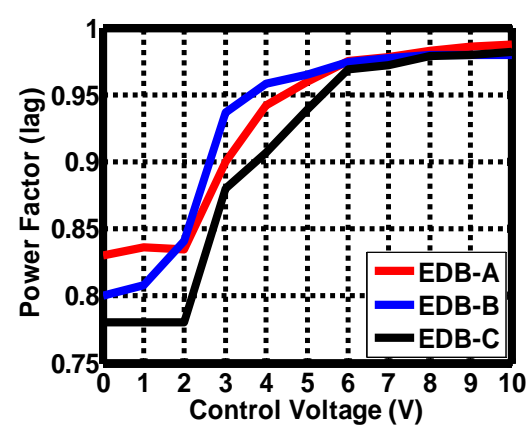

(f)

Figure 1. Measured electrical characteristics over the control voltage dimming range 


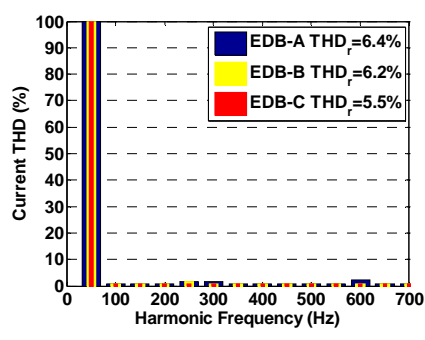

(a)

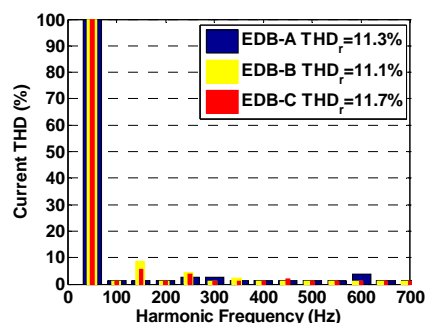

(e)

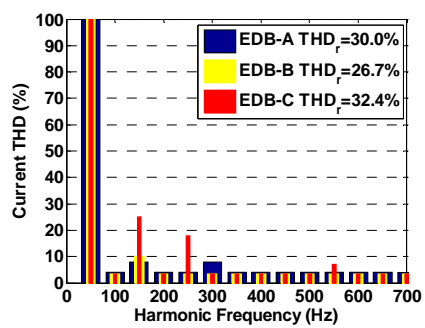

(i)

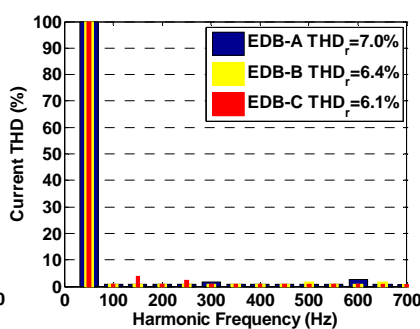

(b)

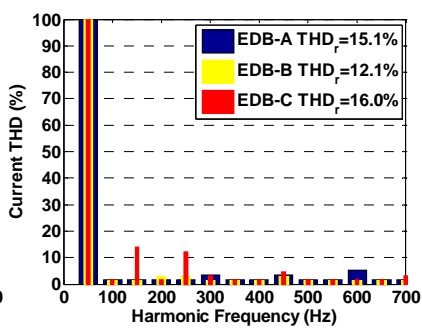

(f)

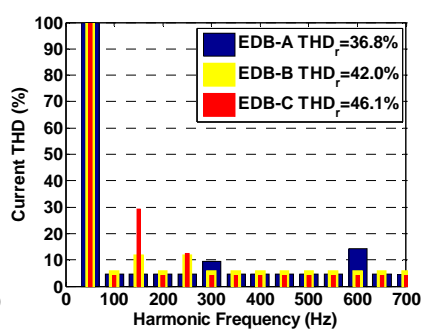

(j)

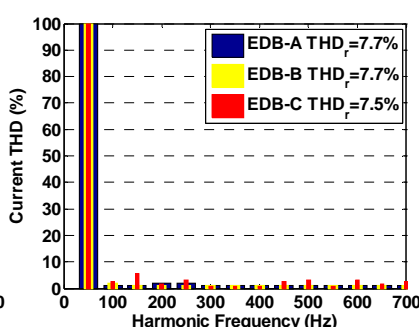

(c)

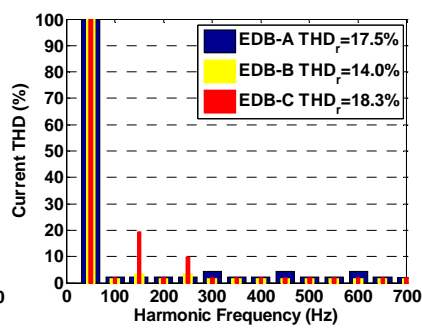

(g)

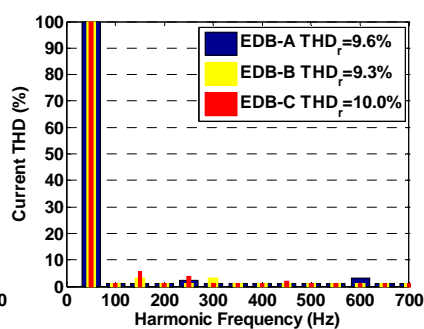

(d)

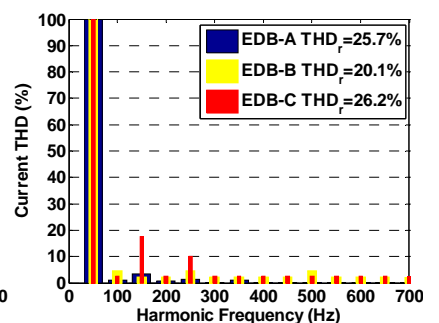

(h)

Figure 2. Current harmonic spectra at decreasing ballast dimming voltages a) $10 \mathrm{~V} \mathrm{~b}) 9 \mathrm{~V} \mathrm{c}$ ) $8 \mathrm{v} \mathrm{d}$ ) $7 \mathrm{v} \mathrm{e)} 6 \mathrm{v} \mathrm{f}) 5 \mathrm{v} \mathrm{g}$ ) $4 \mathrm{~V} \mathrm{~h}$ ) $3 \mathrm{~V} \mathrm{i}$ ) 2V j) $1 \mathrm{~V}$

Figure 1(f) demonstrates the deterioration of power factor with reduction in control voltage. The power factor reduces from approximately 0.98 to $0.83,0.8$ and 0.78 for EDB-A, EDB-B and EDB-C lighting system respectively. This decline in power factor is attributed to surfacing of lower odd order harmonics during dimming. The influence of dimming on power quality is discussed in next Subsection 4.1.1. A mathematical relationship between power factor and harmonics is given by Equation (1) [18].

$$
p \cdot f=\frac{1}{\sqrt{1+T H D^{2}}} \cos (\phi)
$$

Additionally, the electricity supply companies require that the power factor at which the supply is used shall be maintained at not less than 0.9 lagging. Referring to Figure 1(e), for dimming voltages below $3 \mathrm{~V}$ power factor of the tested ballasts lies below 0.9 .

\subsubsection{Power Quality}

Power quality issues are concerned with growing presence of line harmonic distortions characterized by poor power factor. Harmonics are frequencies that are integral multiples of the fundamental frequency. Harmonics emanate whenever the supply wave shape is distorted from a pure sine wave. In electronic ballast system, the narrow current pulses drawn by the conventional rectifier-capacitor type interface is rich in harmonics [19]. A common measure of distortion in current and voltage is defined by percentage Total Harmonic Distortion.

Industry standards for harmonic current distortion fro$\mathrm{m}$ electronic lamp systems have not been formally established [20]. ANSI C82.77 sets a maximum current THD limit of 32\% for the lighting equipment [21]. According to IEEE 519 and IEC 61000-3-2 [22,23], the current THD and voltage THD limits for electronic ballasts is $20 \%$ and 5\% respectively. Current and voltage harmonic spectra for the different lamps used in the study are presented in Figure 2 and Figure 3 respectively. Though the investigated ballasts were equipped with harmonic suppression filters by the manufacturers; the significantly distorted current during dimming is possibly owed to the construction me- thod in order to decrease the ballast size and cost. The bar Figures 2(a)-(j) shows the individual harmonic distortion expressed in percent of the fundamental current as defined by the formula in Equation (2) 


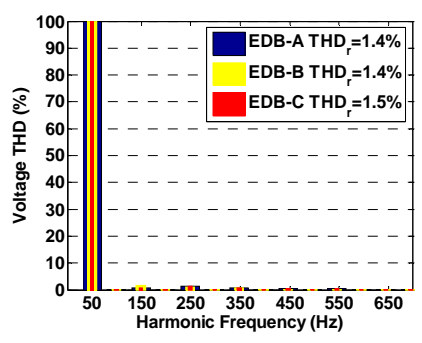

(a)

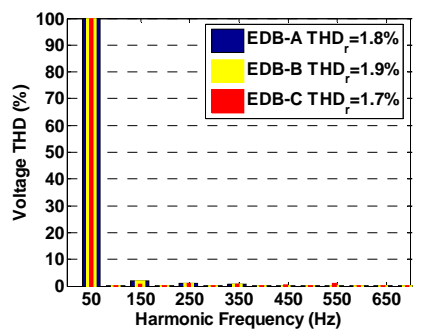

(e)

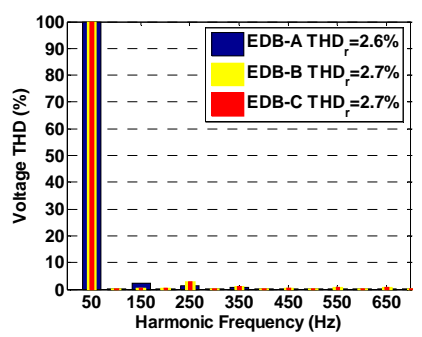

(i)

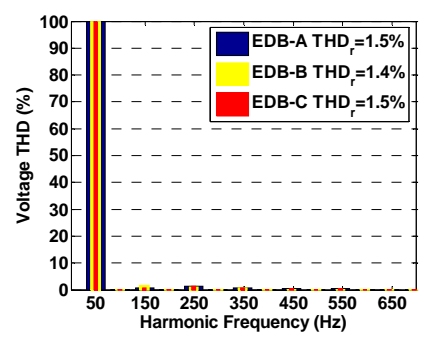

(b)

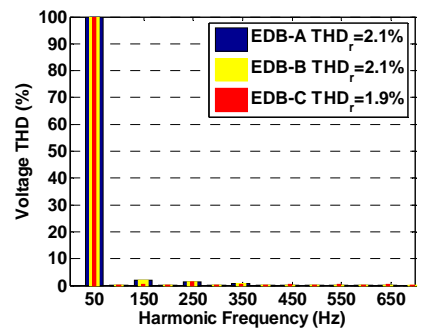

(f)

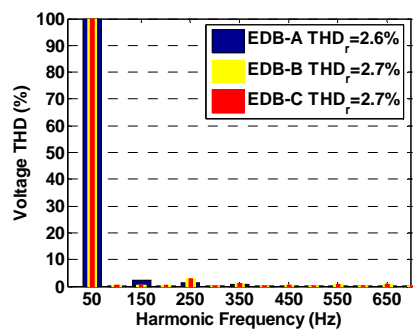

(j)

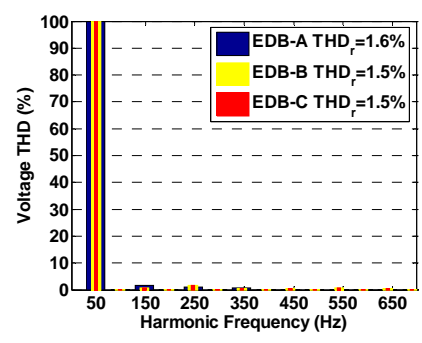

(c)

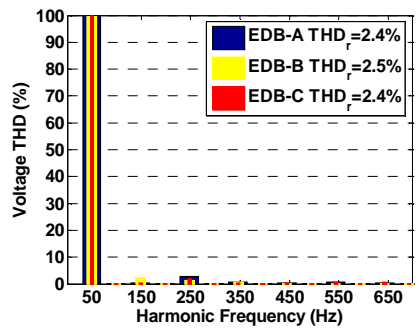

(g)

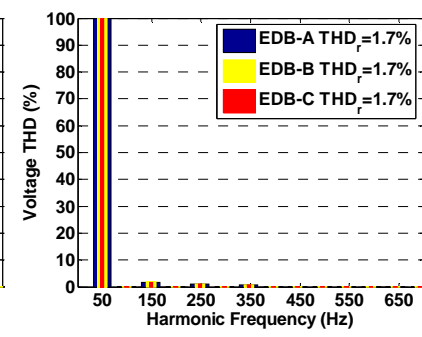

(d)

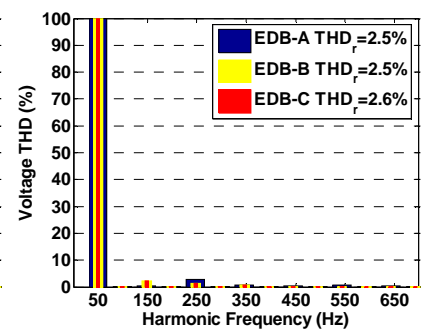

(h)

Figure 3. Voltage harmonic spectra at decreasing ballast dimming voltages a) $10 \mathrm{~V} \mathrm{~b}) 9 \mathrm{~V} \mathrm{c}$ ) $8 \mathrm{v} \mathrm{d}$ ) $7 \mathrm{v} \mathrm{e)} 6 \mathrm{v} \mathrm{f)} 5 \mathrm{v} \mathrm{g}$ ) $4 \mathrm{~V} \mathrm{~h}$ ) $3 \mathrm{~V} \mathrm{i}$ ) 2V j) $1 \mathrm{~V}$

$$
T H D=\frac{\sqrt{\sum_{n=2}^{14} I_{n}{ }^{2}}}{I_{1}}
$$

As depicted in Figure 2(a) through (j) when the lamps are dimmed down from $10 \mathrm{~V}$ to $1 \mathrm{~V}$ the spectrum of current is characterized by emergence and elevation of magnitudes of third and fifth order harmonic components while dimming. Ballast B accounts a lower current THD (except at 1V) compared to other ballast $\mathrm{A}$ and ballast $\mathrm{C}$. On an average for all the ballasts the line current THD increases from a minimum of $6.0 \%$ at $10 \mathrm{~V}$ to maximum of $42.0 \%$ at $1 \mathrm{~V}$. From the measurements results, it is clear that for the reported ballasts; THD in current lies within recommended IEEE 519 for control voltage above $3 \mathrm{~V}$. Similarly, for control voltage more than $2 \mathrm{~V}$ current THD is less than ANSI C82.77 limits. Bar Figures 3(a)-(j) depicts the voltage harmonic spectra during lamp dimming down process. On an average for all the tested ballasts line voltage THD lies between $1.6 \%$ at $10 \mathrm{~V}$ to $2.6 \%$ at $1 \mathrm{~V}$ complying with IEEE 519 standard voltage limit of $5 \%$. Additionally, it is observed during dimming that line current and line voltage crest factor is below 1.7.

\subsection{Effect on Photometric Characteristics}

Table 1 illustrates the influence of dimming on candela power distribution curves and CU values of luminaires under examination. Light distribution curves are curves defining variation of luminous intensity with angle of emission in a C 0-180 and C 90-270 plane, passing though centre of luminaire [24]. Furthermore specifiers use the coefficient of utilization chart to assess how effectively luminaire delivers light to a work plane. Referring to the polar curves presented in column 2 of Table 1; whilst dimming down from 10 to $1 \mathrm{~V}$, EDB-B has a lower light intensity compared to EDB-A and EDB-C. The candela power of the lamp EDB-A is downsized from approximately $2000 \mathrm{~cd} / 1000 \mathrm{~lm}$ to approximately $65 \mathrm{~cd} / 1000 \mathrm{~lm}$. For EDB-B and EDB-C lamps the light intensity value decreases from approximately $1800 \mathrm{~cd} / 1000 \mathrm{~lm}$ to $60 \mathrm{~cd} /$ $1000 \mathrm{~lm}$. It is observed that there is not much deviation in the light distribution contour shape at different dimming levels. However, it is noticed that the light distribution pattern is slightly affected for control voltage less than $4 \mathrm{~V}$ for EDB-C luminaire and below $2 \mathrm{~V}$ for EDB-A and EDB-B lamps respectively, the luminaire efficiency while 
Table 1. Effect of dimming on candela power distribution (II column) and on values of coefficient of utilization (III column) for each dc control voltage (I column)

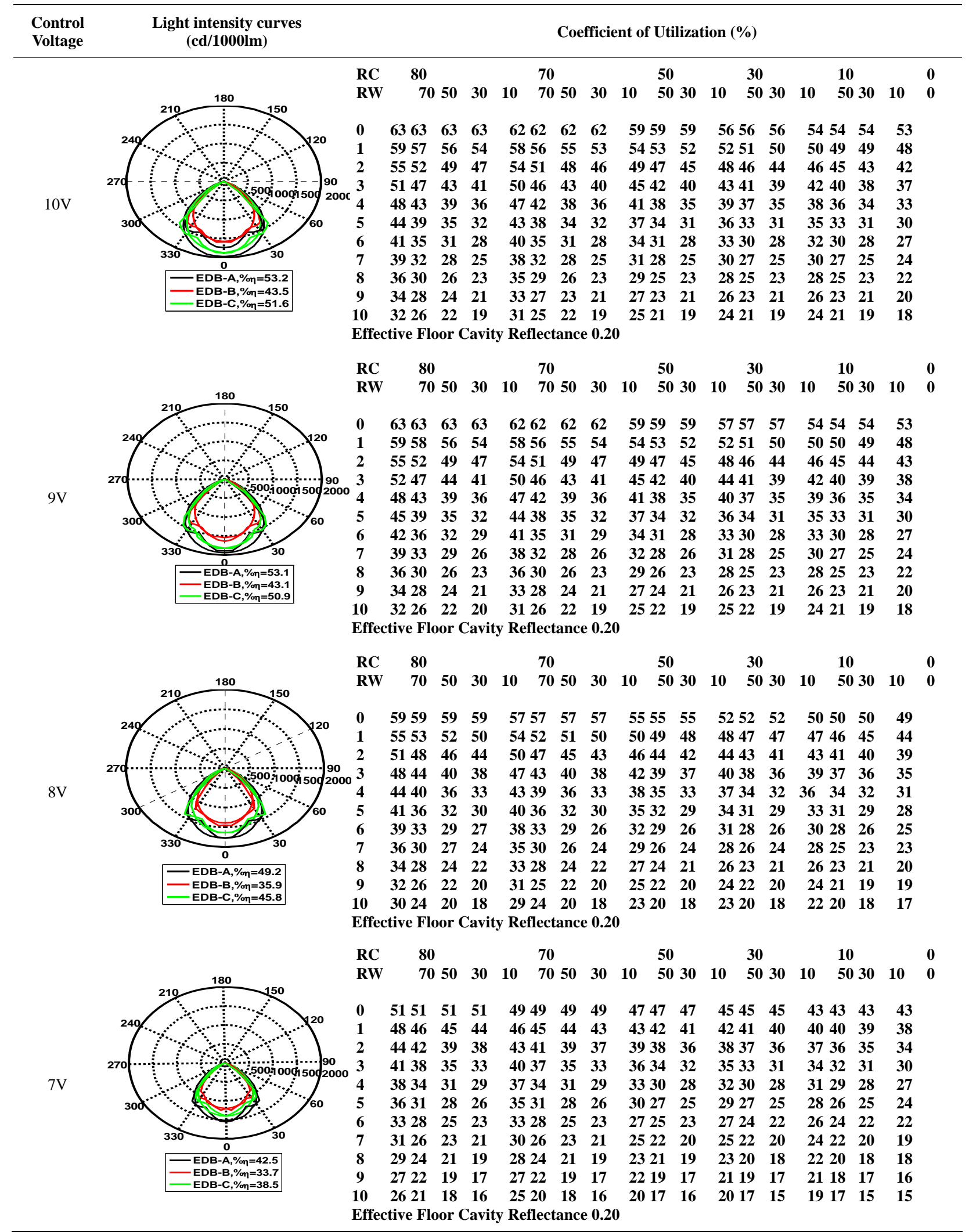



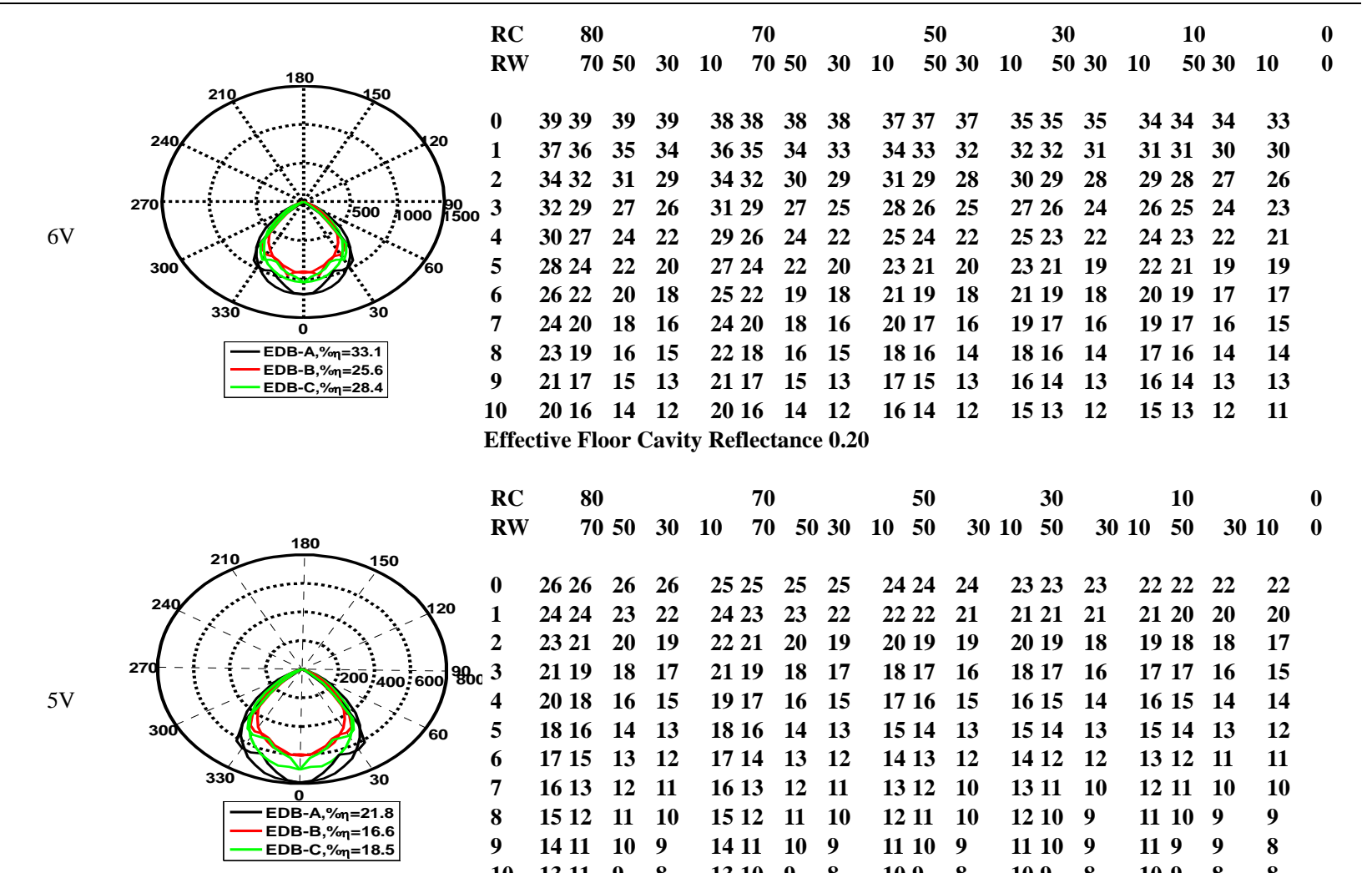

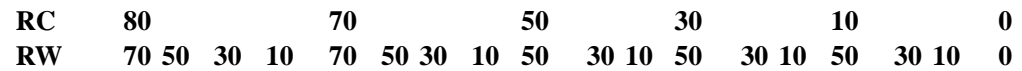

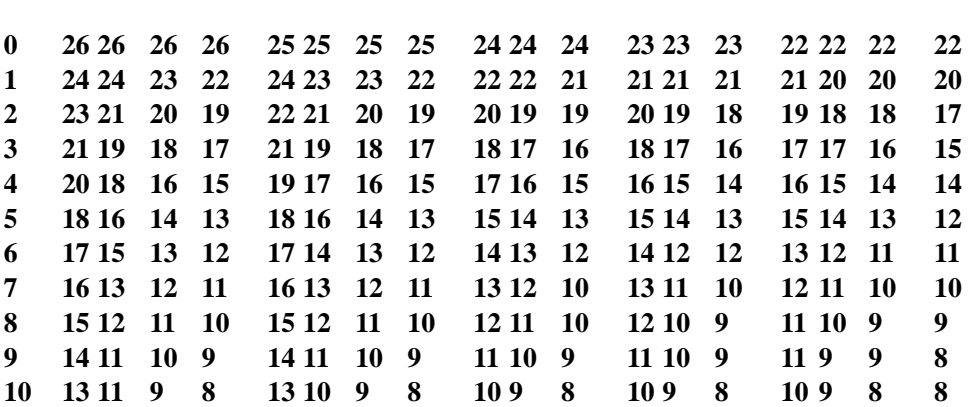

Effective Floor Cavity Reflectance 0.20

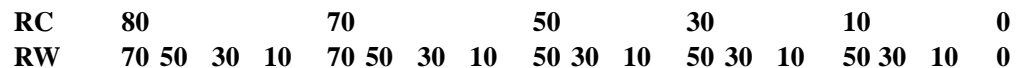

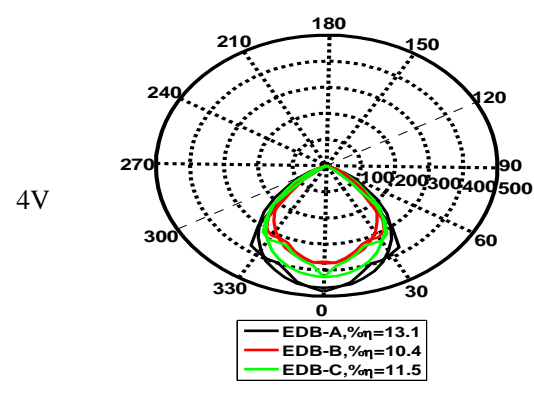

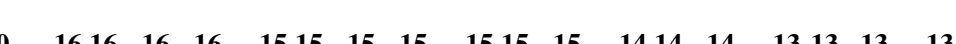

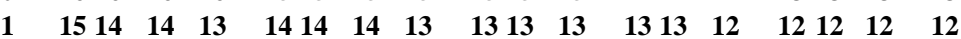

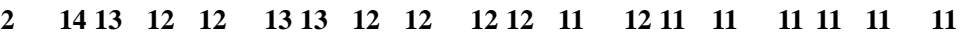

$\begin{array}{lllllllllllllllllll}3 & 13 & 12 & 11 & 10 & 12 & 11 & 11 & 10 & 11 & 10 & 10 & 11 & 10 & 10 & 10 & 10 & 10 & 9\end{array}$

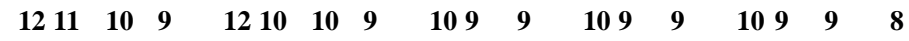

$\begin{array}{llllllllllllllllll}11 & 10 & 9 & 8 & 11 & 10 & 9 & 8 & 9 & 8 & 8 & 9 & 8 & 8 & 9 & 8 & 8 & 7\end{array}$

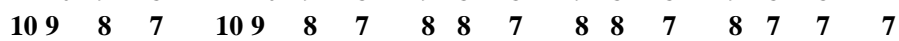

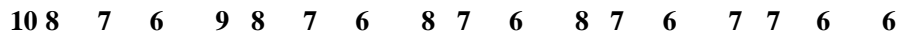

$\begin{array}{llllllllllllllllll}9 & 7 & 6 & 6 & 9 & 7 & 6 & 6 & 7 & 6 & 6 & 7 & 6 & 6 & 7 & 6 & 6 & 5\end{array}$

$\begin{array}{lllllllllllllllllll}9 & 8 & 7 & 6 & 5 & 8 & 7 & 6 & 5 & 7 & 6 & 5 & 7 & 6 & 5 & 6 & 6 & 5 & 5\end{array}$

$\begin{array}{lllllllllllllllllll}10 & 8 & 6 & 5 & 5 & 8 & 6 & 5 & 5 & 6 & 5 & 5 & 6 & 5 & 5 & 6 & 5 & 5 & 5\end{array}$

Effective Floor Cavity Reflectance 0.20

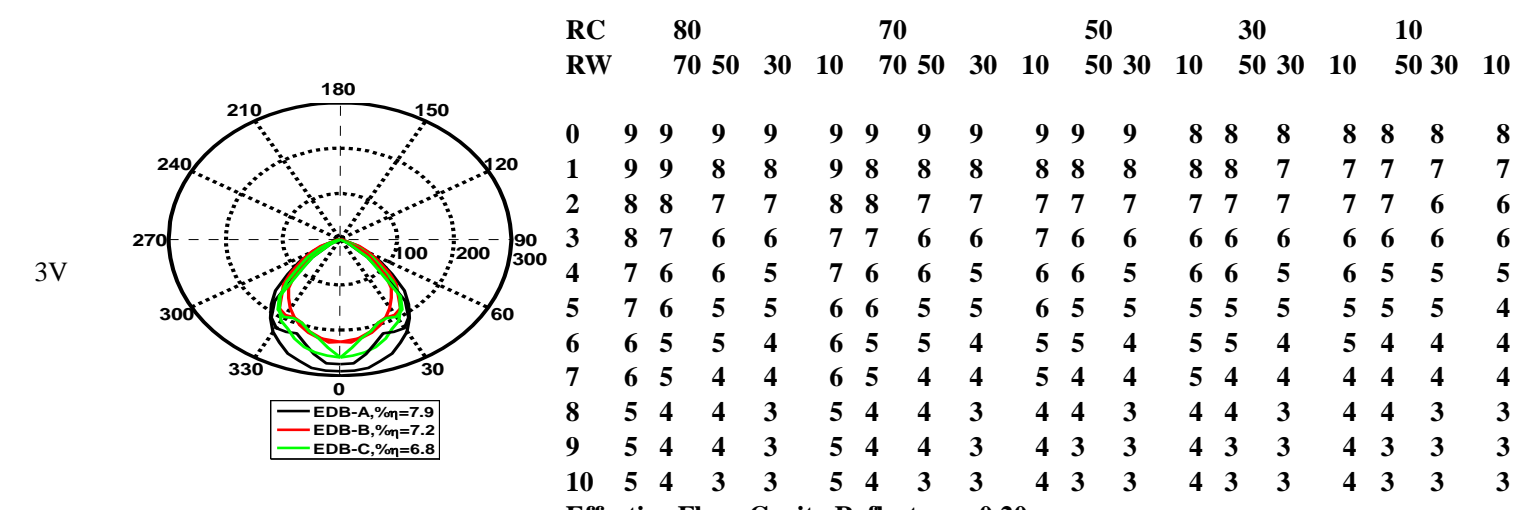

Effective Floor Cavity Reflectance 0.20 


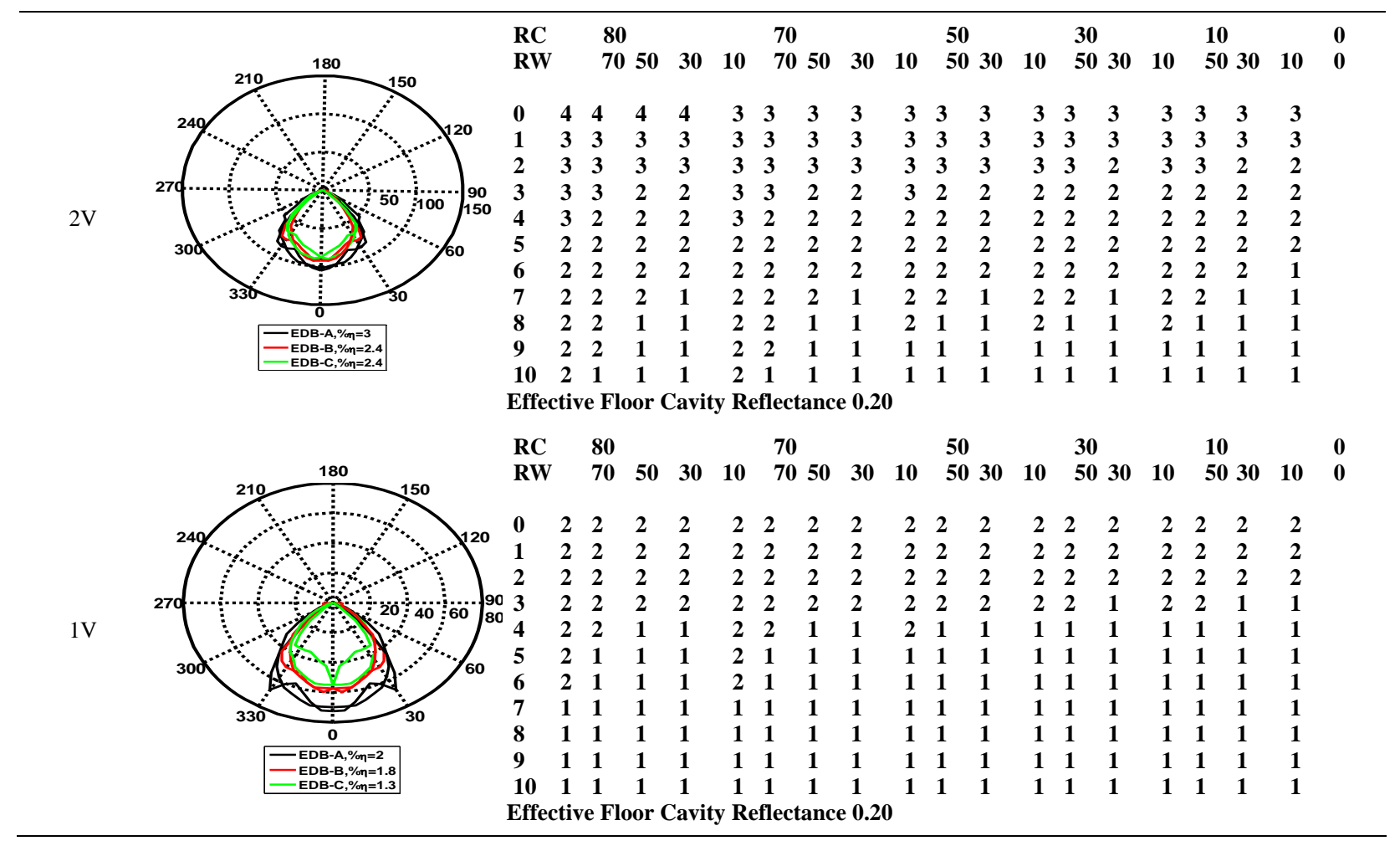
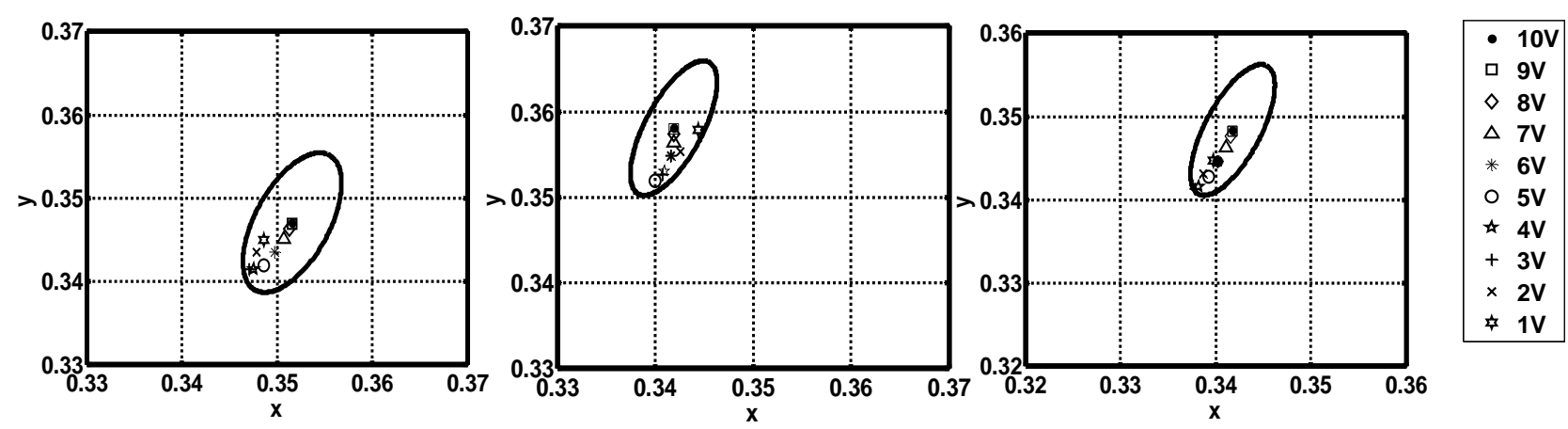

Figure 4. Chromaticity diagrams and Mac Adam ellipses for a)EDB-A b) EDB-B and c) EDB-C lamps

dimming down drops from a maximum of $53.2 \%, 43.5 \%$ and $51.6 \%$ to a minimum of $2 \%, 18 \%, 1.8 \%$ for EDB-A, EDB-B, EDB-C respectively due to decrease in the ballast control voltage. Taking the representative case of EDB-A luminaire, tabulated percentage CU values generated by AGI-32 Photometric toolbox is shown in third column of Table 1 against each ballast control voltage. The row labeled RC is the effective ceiling reflectance, the row labeled RW is the wall reflectance and the first column is the Room Cavity Ratio. For the indicated ceiling, wall and room cavity ratios, the tabulation shows the percentage of utilized lumens on the work plane. Clearly, percentage $\mathrm{CU}$ value of the luminaire depreciates with the reduction in the control voltage.

\subsubsection{Chromaticity and CCT}

Chromaticity values are customarily used for characterizing the color appearance of a light source. A metric commonly used for quantifying perceivable color difference is the MacAdam ellipse, which is a contour in the chromaticity diagram [25]. The ANSI specifies a 4-step MacAdam ellipse as the acceptable chromaticity tolerance area for certain types of fluorescent lamps [26]. Almost all color-normal subjects will perceive a color difference in source if the chromaticity coordinates of experimental light source in the course of dimming; falls beyond chromaticity tolerance area. Using the chromaticity coordinates of maximum output as the centre of the ellipse, 4 steps MacAdam ellipse plotted for the reported ballasts are shown in Figure 4 (a) through (c). As can be 


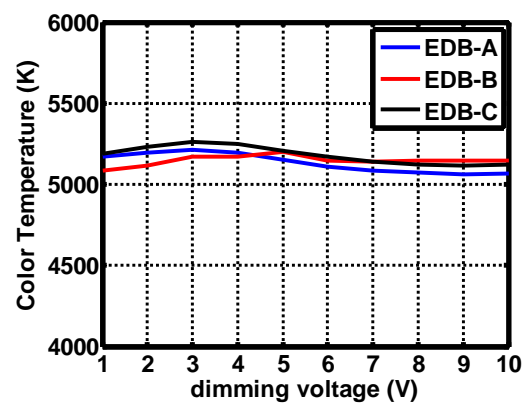

Figure 5. CCT(K) versus ballast analog control voltage

seen from the Figure 4 all the experimental lamps in question subjected to dimming confines their chromaticity shift within 4-step MacAdam ellipse. Further it is noticed that $\mathrm{X}$ - Y chromaticity coordinates remain essentially constant throughout the dimming range. Figure 5 indicates the relative CCT shift for various dimming control voltage of the ballast. It is observed that there is no appreciable deflection in CCT all through the dimming voltage range.

\subsection{Effect on Visual Performance}

This section highlights on the influence of fluorescent lamp dimming systems on quantity and quality of interior illuminance. Figure 6 (a) through (j) portrays the simulated view of standard office room $(2.0 \times 2.0 \times 3.0 \mathrm{~m})$ rendered by Relux lighting simulation software. In addition Matlab generated 3D mesh plot of interior horizontal illuminance for each control voltage of the ballast is illustrated in Figures 6(a)-(j). Reflections of the floors, walls and ceiling are considered to be diffuse with reflection coefficients of $0.3,0.5$ and 0.7 respectively. For elucidation, this paper documents the artificial lighting analysis just with EDB-A luminaire. The results presented in this section concentrates on impact of T8 fluorescent lamp dimming on quantity of quality of artificial lighting without daylight intervention into the experimental room under examination. Further, the assessment of perceived discomfort glare due to lighting is not taken into consideration. The simulated 3D illuminance takes into account $0.5 \mathrm{~m}$ offset from the walls at a horizontal working plane $0.7 \mathrm{~m}$ above the floor. The recommended visual performance criterion advocates a minimum average illuminance value at the workplane as $300 \mathrm{~lx}$ and uniformity (ratio of minimum illuminance to average illuminance) above $0.8[27,28]$. Rendered scenes depicted in Figure 6(a)-(j) disclose that there is no perceptible difference in the appearance of the light as well as general appearance of the interior especially related to color. The reason may be that, there is no significant deflection in CCT as well as light distribution pattern of lamp all through dimming as highlighted in the previous sections. However in practical schemes the general brightness of the room depreciates slightly during dimming which could be perceived by the normal observer. This is due to the fact that many working interiors appear dim for illuminance value lower than $200 \mathrm{~lx}$ which is the minimum recommended illuminance for a work space. As represented in Figure 6, illuminance value lower than $200 \mathrm{~lx}$ manifests for dimming voltages beneath 6V. Nevertheless through out dimming uniformity of illuminance in the whole interior stays above 0.8 as displayed in illuminance distribution plots of Figures 6(a)-(j).

\section{Conclusions}

As an energy conservation strategy, dimming controls for electric lighting have been one of the mainstays of the effort to use daylighting. In view of this, the present communication experimentally examined the fluorescent lamp dimming implications on performance characteristics of lighting systems from non manufacturer's perspective. The purpose was to discover acceptable range of dimming control voltage that would gratify both electrical and photometric performance of luminaire. We recognize that there may be a few high frequency electronic dimmable ballasts which are indeed as per national /international specifications. However, our conclusions are limited to the ballasts obtained from afore mentioned manufacturers for our experiments. The following salient points can be gleaned from the experimental results presented in this paper:

- $\quad$ The measurement on electrical characteristics shows, all the tested lamps could be dimmed down from $100 \%$ to $1 \%$ of light output with a power consumption of approximately $20 \%$ at $1 \mathrm{~V}$ d.c. Further, neither the lamp flickers nor extinguishes even at minimum control voltage of $0 \mathrm{~V}$ d.c. During dimming down on an average current THD and voltage THD rises from approximately $6.0 \%$ to $45 \%$ and $1.4 \%$ to $2.7 \%$ respectively. As a consequence the power factor deteriorates from approximately 0.98 at $10 \mathrm{~V}$ to 0.8 at $1 \mathrm{~V}$.

- With respect to photometric performance characteristics, it is inferred that during dimming there is no significant variation in light intensity distribution pattern, CCT and chromaticity shift. On an average for all the tested lamps, the light intensity value drops off from approximately $2000 \mathrm{~cd} / 1000 \mathrm{~lm}$ to approximately $25 \mathrm{~cd} /$ $1000 \mathrm{~lm}$. There is also a significant drop in utilization factor values during dimming. The desired limits of utilization factor depend on task application.

- $\quad$ Rendered simulation results depict no significant variation in visual performance characteristics during dimming as; standards prescribed illuminance uniformity criterion of 0.8 is met. During dimming, average illuminance value dwindles from approximately $520 \mathrm{~lx}$ to $20 \mathrm{~lx}$. However, in practical schemes the interiors appear dim for illuminance values lower than 200lx. Therefore, the judgment of desired lux level for a range of dimming 

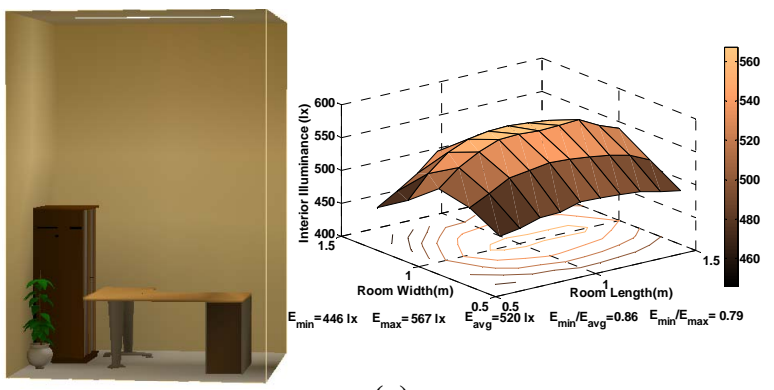

(a)
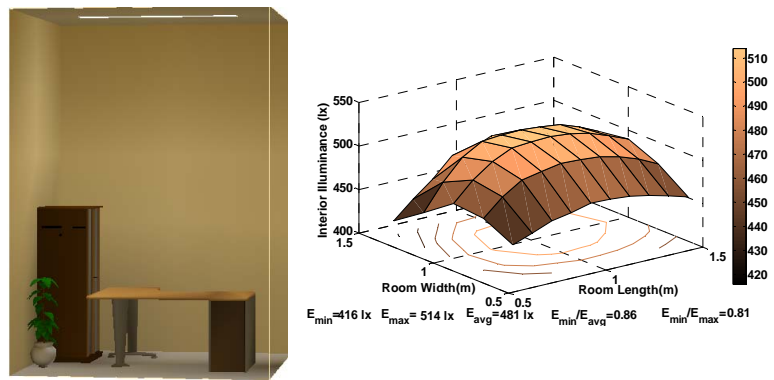

(c)
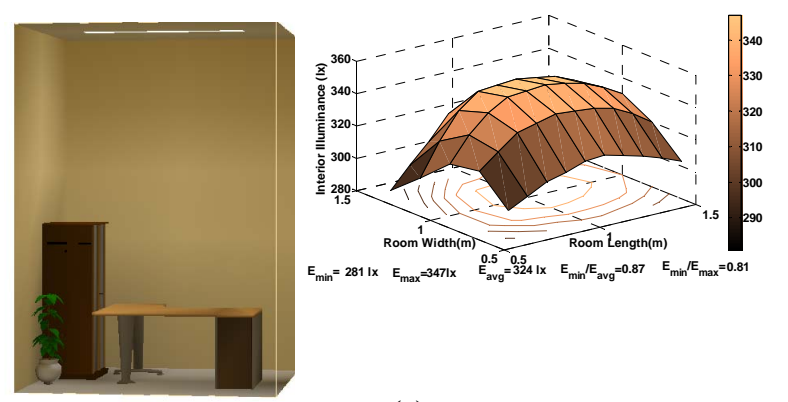

(e)
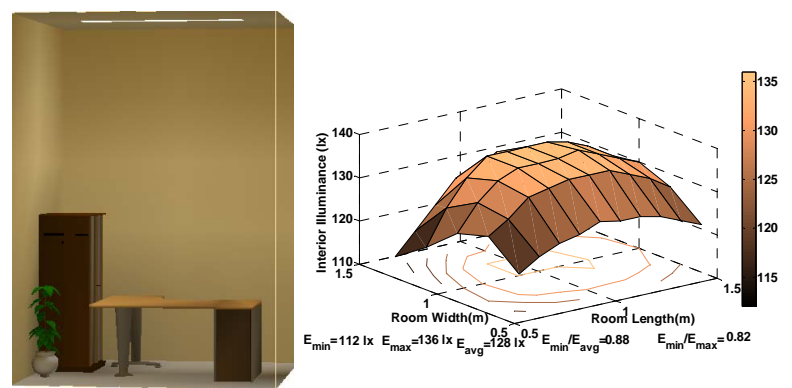

(g)
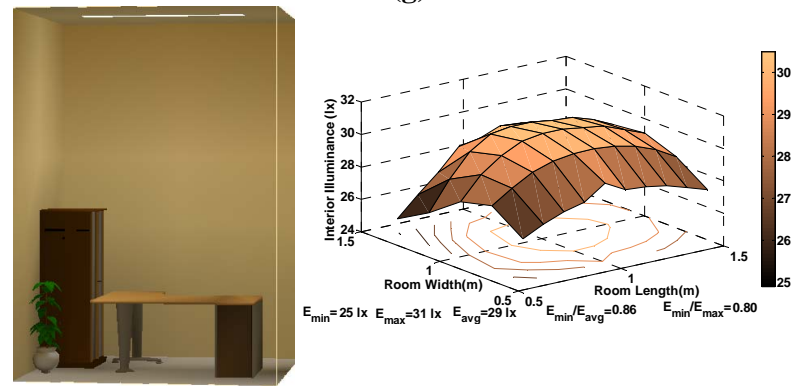

(i)
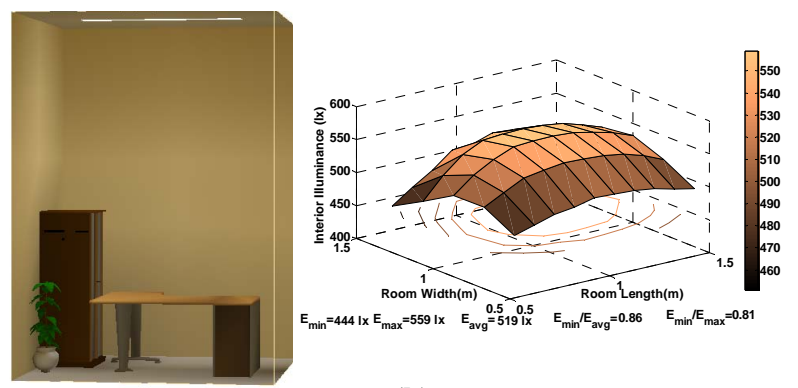

(b)
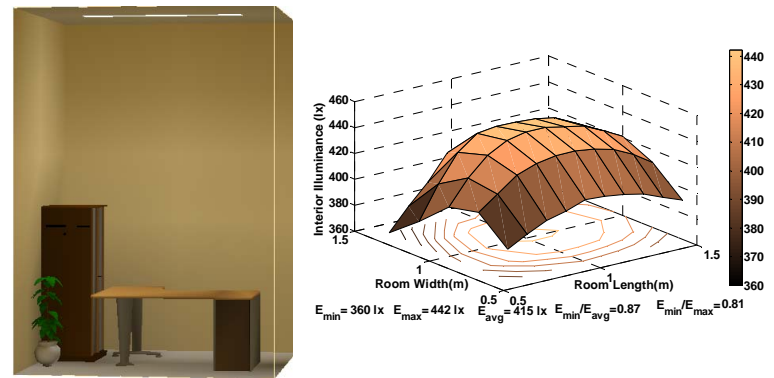

(d)
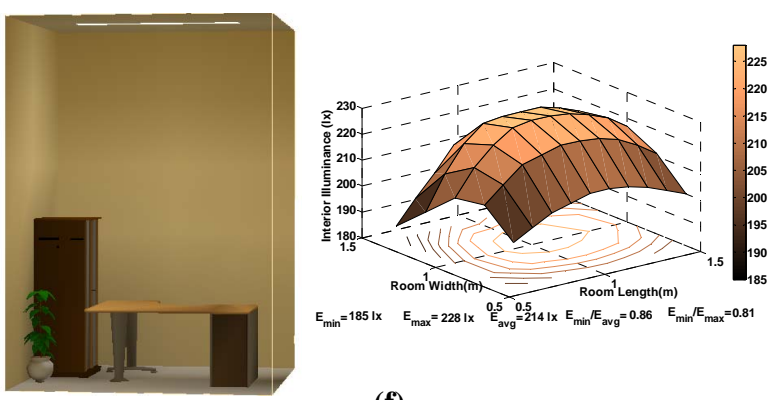

(f)
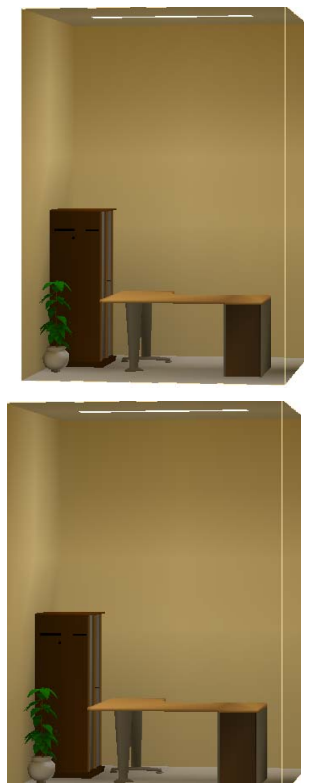

(h)

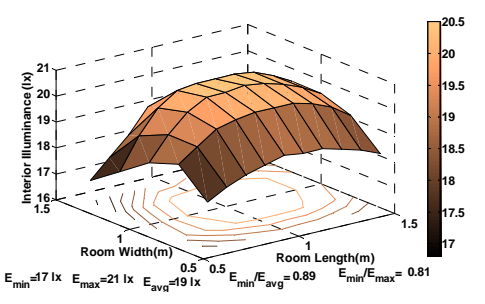

(j)

Figure 6. Visualizing image and corresponding mesh plot of illuminance distribution depicts the influence of dimming on quality and quantity of interior lighting at each dimming voltage a) $10 \mathrm{~V} \mathrm{~b}$ ) $9 \mathrm{~V} \mathrm{c}$ ) $8 \mathrm{v} \mathrm{d}$ ) $7 \mathrm{v}$ e) $6 \mathrm{v} \mathrm{f}$ ) $5 \mathrm{v} \mathrm{g}$ ) $4 \mathrm{~V} \mathrm{~h}$ ) $3 \mathrm{~V} \mathrm{i)} 2 \mathrm{~V} \mathrm{j}$ ) $1 \mathrm{~V}$ 
control voltage requires particular attention based on task application.

In summary it is concluded from our experimental analysis that in order to achieve superior electrical, photometric as well as visual performance from a luminaire; the optimum control voltage range of ballast dimming should preferably lie between $10 \mathrm{~V}$ to $3 \mathrm{~V}$ d.c. The laboratory result of this paper demonstrate that fluorescent lamp dimming schemes are not an obstacle for wider use of energy efficient daylight artificial light integrated schemes.

\section{Acknowledgements}

The present research is funded by Department of Science \& Technology under WOS-A scheme, Government of India. The authors gratefully acknowledge this contribution. Any opinions, findings and conclusions or recommendations expressed in this material are of the authors.

\section{REFERENCES}

[1] S. G. Colaco, C. P. Kurian, V. I. George, and A. M. Colaco, "Prospective techniques of effective daylight harvesting in commercial buildings by employing window glazing, dynamic shading devices and dimming control-A literature review," Building Simulation, Vol. 1, No. 4. P. 279-289, 2008.

[2] C. P. Kurian, R. S. Aithal, J. Bhat, and V. I. George, "Robust control and optimization of energy consumption in daylight-Artificial light integrated schemes," Lighting Research and Technology, Vol. 40, No. 4, pp. 7-24, 2008.

[3] M. S. Rea, "Lighting handbook: Reference and application,” Illuminating Engineering Society of North America (IESNA), 9th Edition, New York, 2000.

[4] C. D. Louie, "Linear fluorescent dimming ballasts: Technology, methods,” Protocols Lighting Controls Association, 2004,

http://www.aboutlightingcontrols.org/education/papers/di mming.shtml)

[5] E. Tetri and V. Gligor, "Dimming according to daylighteffect on lamp life,” Right Light 5, Proceedings of the 5th European Conference on Energy-Efficient Lighting. Nice, France, pp. 421-424, 2002.

[6] Y. Akashi and J. Neches, "Detectability and acceptability of. illuminance reduction for load shedding," Journal of Illuminating Engineering Society, Vol. 33, No. 1, pp. 313, 2004.

[7] M. Etezadi-Amoli and T. Florence, "Power factor and harmonic distortion characteristics of energy efficient lamps,” IEEE Transactions on Power Delivery lamps, Vol. 4, No. 3, pp. 1965-1969, 1989.

[8] J. Yunfen, D. Robert, C. O'Rourke, E. Wai Mun Chui, "Compatibility testing of fluorescent lamp and ballast systems," IEEE Transactions on Industry Applications Vol. 35, No. 6, pp. 1271-1276, 1999.
[9] “Dimming Electronic Ballasts,” National Lighting Product Information Program Specifier Reports, Troy, Lighting Research Center, NY, Rensselaer Polytechnic Institute, Vol. 7, No. 3, October 1999.

[10] R. Benoit, A. Deneyer, P. D’Herdt, and S. M. Diga, “Performance evaluation of dimmable lighting sources with fluorescent tubes for indoor applications,” Proceedings of International Lighting Symposium, Modern Quality Solutions for an Efficient Lighting, Sinaia, Romania, October 12-14, 2006

[11] L. Doulos, A. Tsangrassoulis, and F. Topalis, "Quantifying energy savings in daylight responsive systems: The role of dimming electronic ballasts,” Energy and Buildings, Vol. 40, No. 1, pp. 36-50, 2008.

[12] Commission internationale de l'éclairage, "The measurement of absolute luminous intensity distributions,” CIE Technical Report, No. 70, 1987.

[13] Commission internationale de l'éclairage, "The photometry and goniophotometery of luminaires,” CIE Technical Report, No. 121, 1996.

[14] Illuminating Engineering Society of North America (1999), IESNA guide to lamp seasoning, IES committee on testing procedures IES LM-54- 9,. New York.

[15] Illuminating Engineering Society of North America, "IESNA approved method for electrical and photometric measurements of fluorescent lamps,” IES comitee on testing procedures IES LM-9-99, New York, 1999.

[16] Matlab R2009a version 7.5 user manual, http://www.mathworks.com.

[17] A. Choi, K. Song, and Y. Kim, "The characteristics of photosensors and electronic dimming ballasts in daylight responsive dimming systems," Building and Environment, Vol. 40, pp. 39-50, 2005

[18] F. V. Topalis, "Efficiency of energy saving lamps and harmonic distortion in distribution systems," IEEE Transactions on Power Delivery, Vol. 8, No. 4, pp. 20382042, 1993.

[19] T. Jednacz, "Power quality design implications of high frequency lighting ballasts and controls,” Industry Applications Society Annual Meeting, Vol. 2, pp. 1833-1835, 1991.

[20] R. Wolsey, "Lighting answers: power quality,” Lighting Research Center, Rensselaer Polytechnic Institute, Vol. 2, No. 2, 1995, http://www.sdeg.org/docs/LAPQ.pdf.

[21] Harmonic Emission Limits-Related Power Quality Requirements for Lighting, American National Standards Institute (ANSI), C82.77, New York, 1993.

[22] IEEE recommended practice and requirements for harmonic control in electrical power systems, IEEE standard pp. 519, 1992

[23] Limits for harmonic current emission equipment input current $\leq 16$ A per phase (2004) International Electrotechnical Commission (IEC) Edition 2.2

[24] C. P. Kurian, R. S. Aithal, and S. G. Colaco, "Performance evaluation of lamp-luminaire combination: A software approach using MATLAB," Journal of Institution of 
Engineers, Vol. 85, pp. 98-101, 2004.

[25] G. Wyszecki and W. S. Stiles, Color Science, Wiley, New York, 1982.

[26] "American national standard for electric lamps: Specifications for the chromaticity of fluorescent lamps," American National Standards Institute (ANSI) C78.376, National Electrical Manufacturers Association, Rosslyn, VA, 2001.
[27] Code Bureau of Indian Standards, Code of practice for interior illumination: Part 1 General requirements and recommendations for working interiors IS 3646, Part 1, Section 0, 1992, Reaffirmed 2003

[28] R. Yarham, Code for Interior Lighting Chartered Institution of Building Services Engineers (CIBSE), London, 1994.

\section{Nomenclatures:}

$\eta \quad$ Luminaire efficiency

$\cos (\phi) \quad$ Cosine of the phase angle between input voltage and current.

$I_{1} \quad$ Fundamental current (A)

$I_{n} \quad$ Current at harmonic order number $n$ $p f$

THD

CCT

$\mathrm{CU}$

$\mathrm{E}_{\min }$

$E_{\max }$

$E_{\text {avg }}$
Power factor given by $\cos (\phi)$

Total Harmonic Distortion

Correlated Color Temperature (K)

Coefficient of Utilization

Minimum Illuminance (lx)

Maximum Illuminance (lx)

Average Illuminance (lx) 